\title{
Fusayolas de la necrópolis de Olival do Senhor dos Mártires (Alcácer Do SAL, Portugal): TIPOLOGÍA, FUnCIÓN Y SIMBOLISMO \\ Spindle-whorls from the Necropolis of Olival do Senhor dos Mártires (Alcácer do Sal, Portugal): Typology, Function and Symbolism
}

FRANCISCO B. GOMES 무

UNIARQ - Centro de Arqueologia da Universidade de Lisboa. Facultade de Letras da Universidade de Lisboa. FCT. franciscojbgomes@gmail.com

RESUMEN:

La presencia de un conjunto significativo de fusayolas entre los ajuares de la necrópolis de la Edad del Hierro de Olival do Senhor dos Mártires (Alcácer do Sal, Portugal) plantea cuestiones de gran interés sobre los límites entre la función de estos elementos y su significado simbólico y escatológico. En este estudio se abordan esas cuestiones, analizando por un lado las características físicas, tecnológicas y morfológicas de las piezas, y por otro los posibles códigos simbólicos y religiosos que las convierten en elementos integrales del ajuar funerario en distintas comunidades del sur peninsular.

Palabras clave: fusayolas, Edad del Hierro, tecnología textil, simbología funeraria, Olival do Senhor dos Mártires (Alcácer do Sal, Portugal).

Abstract:

The presence of a significant number of spindle-whorls among the votive offerings of the Iron Age necropolis of Olival do Senhor dos Mártires (Alcácer do Sal, Portugal) poses interesting questions regarding the boundary between the functional role of these elements and their symbolic and scatological significance. In this contribution those questions are addressed, on the one hand, through an analysis of their physical, technological and morphological characteristics; on the other, by assessing the possible symbolic and religious context which makes them an integral part of the funerary offerings in different communities of the southern Iberian Peninsula.

Key words: spindle-whorls, Iron Age, textile technology, funerary symbolism, Olival do Senhor dos Mártires (Alcácer do Sal, Portugal).

Copyright: (C) 2017 Francisco B. Gomes. This is an open access paper distributed under the terms 


\section{LA NECRÓPOLIS DE OLIVAL DO SENHOR DOS MÁRTIRES: BREVE INTRODUCCIÓN}

La necrópolis de Olival do Senhor dos Mártires (OSM), ubicada a $1 \mathrm{~km}$ al O del castillo medieval de Alcácer do Sal (fig. 1), fue identificada de modo accidental a finales del s. XIX durante unos trabajos agrícolas que dieron como resultado el descubrimiento de un importante lote de materiales.

La importancia de dicho conjunto funerario se reconoció enseguida tras la publicación preliminar de estos materiales (Silva 1875; Veiga 1890), aunque los primeros trabajos arqueológicos sistemáticos se desarrollaron mucho

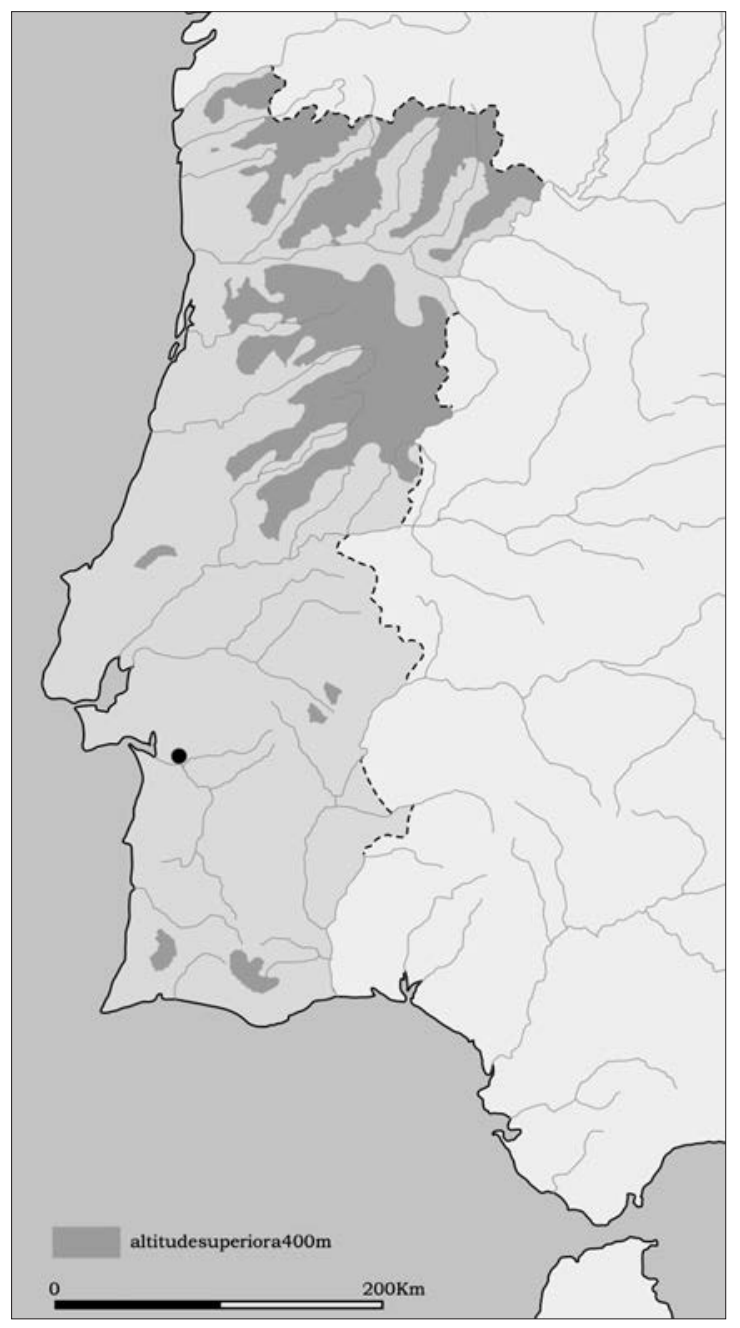

Fig. 1: Ubicación de la necrópolis de Olival do Senhor dos Mártires (OSM) (base cartográfica de V. S. Gonçalves). más adelante. De hecho, las primeras excavaciones en la necrópolis tuvieron lugar en los años veinte, cuando Vergílio Correia asumió la investigación del yacimiento y llevó a cabo en él un extenso programa de excavaciones entre 1925 y 1927.

Lamentablemente, el Profesor de la Universidad de Coimbra no llegó nunca a realizar la publicación detallada de los resultados de estos trabajos, pero sí redactó una serie de artículos que aún constituyen la base fundamental del conocimiento sobre la ocupación de la necrópolis (Correia 1925a [1971]; 1925b [1971]; 1925c [1971]; 1927 [1971]; 1930 [1971]).

En décadas posteriores, aunque no se dio continuidad a las intervenciones en el yacimiento, se siguieron estudiando los materiales recogidos tanto en los trabajos agrícolas del s. XIX como en las excavaciones de V. Correia (Arthur 1952; Pereira 1962; Schüle 1969; Brito 1969).

A finales de los sesenta se reanudaron los trabajos de campo en la necrópolis, ahora bajo la dirección de António Cavaleiro Paixão, cuya primera campaña de excavaciones se publicó con gran detalle en su Tesis de Licenciatura (Paixão 1970; cf. tb. Paixão 2014). Sin embargo, y desafortunadamente, los resultados de las siguientes campañas realizadas por este investigador a finales de los años setenta e inicios de los ochenta prácticamente no se han dado a conocer hasta el momento ( $c f$. Paixão 1983; 2001).

Tras estos trabajos, y con la excepción de algunos nuevos estudios de materiales específicos (Ponte 1985; Rouillard et al. 1988-1989), se publicaron pocos datos sobre este conjunto funerario. Aun así, cabe destacar los intentos de sistematización de la información disponible a finales del siglo pasado por distintos investigadores (Fabião 1998: 350-366; Torres Ortiz 1999: 114-115; Arruda 1999-2000: 72-86), que sentaron las bases de la discusión contemporánea sobre la necrópolis, su secuencia de utilización y su marco cronológico y cultural.

No obstante, faltaba realizar un estudio sistemático de los ajuares funerarios recogidos en las distintas campañas de excavación del yacimiento, trabajo que he acometido en el marco de mi tesis doctoral (Gomes 2016) y que ha permitido arrojar nuevos datos a las reflexiones de los investigadores citados y establecer, con ciertas garantías de seguridad, la secuencia general y las fases de utilización del conjunto funerario (id.: 345-350).

No es éste el contexto apropiado para discutir dicha secuencia de ocupación; sin embargo, se puede señalar que la necrópolis de OSM ha conocido una ocupación continuada entre, al menos, los ss. VII y IV-III a.n.e., y posiblemente 
incluso hasta época romana, presentando una interesante evolución in situ tanto de los ritos funerarios propiamente dichos como de las prácticas y discursos sociales que se materializan en los ajuares que acompañaban a los difuntos. En todo caso, a lo largo de todo este período, la necrópolis muestra una afinidad continuada con los territorios meridionales de la península Ibérica y, de un modo más general, con el ámbito cultural del Mediterráneo (Fabião 1998: 350-366; Torres Ortiz 1999: 114-115; Arruda 19992000: 72-86; Gomes 2015; 2016: 345-350).

\section{LAS FUSAYOLAS DE LA NECRÓPOLIS DE OLIVAL DO SENHOR DOS MÁRTIRES: UNA APROXIMACIÓN TECNO-TIPOLÓGICA}

\section{CUANTIFICACIÓN Y DATOS CONTEXTUALES}

En el marco del estudio integral de los ajuares de la necrópolis de OSM anteriormente comentado (Gomes 2016) he identificado un significativo conjunto de elementos relacionados con prácticas de producción textil, y en particular con el hilado, que constituye el objeto del presente estudio (figs. 2, 3 y 4).

Este conjunto está compuesto por 56 fusayolas cerámicas ${ }^{1}$, que suponen un $8,4 \%$ del total del material cerámico exhumado en el yacimiento. A este conjunto puede sumarse todavía otra pieza que debe en mi opinión interpretarse como un rocadero, es decir, un elemento que se utilizaría no ya como contrapeso durante el proceso de hilado sino más bien aplicado en la extremidad superior de la rueca para contener la masa de fibras destinada a alimentar la acción del huso.

Lamentablemente, resulta imposible determinar el contexto específico de estas piezas, ya que las múltiples intervenciones en el yacimiento han dado como resultado una pérdida casi total de la documentación de campo y de la información sobre el contexto de los ajuares. Sin embargo, puede asegurarse sin lugar a duda que estas piezas pertenecen a contextos sepulcrales, ya que V. Correia se refiere de forma específica a la presencia de fusayolas en tumbas pertenecientes a los Tipos $1^{\circ}, 3^{\circ}$ y $4^{\circ}$ de su clasificación (Correia 1928 [1971]: 173 y 176-177) en la descripción sintética de los grupos de tumbas que identificó en la necrópolis.

Con respecto a los depósitos del Tipo $1^{\circ}$-incineraciones con deposición secundaria de las cenizas en urnas colocadas en hoyos simples excavados en el terreno, fechables en la II Edad del Hierro ( $c f$. Fabião 1998: 357366; Arruda 1999-2000: 72-86)-, este investigador se refiere de forma explícita a las ...duas coçoiras ou fusaïolas rituais que acompañarían al cadáver (Correia 1928 [1971]: 173), lo cual podría indicar que estos elementos se depositaban normalmente formando pares. No obstante, dicha situación podría deberse igualmente a la presencia de más de un individuo depositado en una misma tumba, hecho que parece haberse producido en algunos casos (ibidem).

Quizás más sorprendente sea la información, transmitida también por este mismo investigador, de que las fusayolas integraban ya los ajuares de las tumbas de sus Tipos $3^{\circ}$ y $4^{\circ}-$ busta en fosa excavada en la roca, de sección simple o con canal central, respectivamente, característicos de las fases de la I Edad del Hierro en la necrópolis (cf. Arruda 1999-2000: 72-86; Gomes 2015)-, ya que el período de mayor difusión de este tipo de piezas, y sobre todo de su incorporación a los ajuares funerarios, no es anterior en otros contextos a la segunda mitad del I milenio a.n.e. ( $c f$. infra).

Así, parece claro que estos instrumentos relacionados con la actividad textil se incorporaron de forma relativamente precoz a los ajuares de la necrópolis de Alcácer do Sal, manteniéndose esta práctica a lo largo de la II Edad del Hierro, cuando quizás se vio reforzada, como adelante se comentará, por fenómenos de convergencia cultural y ritual con otras áreas de la península Ibérica. Antes de abordar estos aspectos cabría, sin embargo, analizar más detalladamente las piezas en cuestión.

\section{ASPECTOS TÉCNICOS, PRODUCTIVOS Y DECO- RATIVOS}

Desde el punto de vista técnico cabría señalar, en primer lugar, que las fusayolas (y el rocadero) de OSM parecen haber sido producidos en su mayoría a mano (52 piezas, es decir, un 91,2\% del total), aunque también se puedan contabilizar cinco piezas $(8,8 \%$ del total) que, por presentar configuraciones más regulares y simétricas, podrían quizás haberse producido con molde.

A pesar de esta relativa homogeneidad técnica, el panorama obtenido mediante el análisis macroscópico de las piezas evidencia cierta heterogeneidad productiva. De hecho, y en función de las características de las arcillas utilizadas en su conformación y de las cocciones a que se han sometido las piezas, se pueden diferenciar tres grupos distintos: 
Francisco B. Gomes

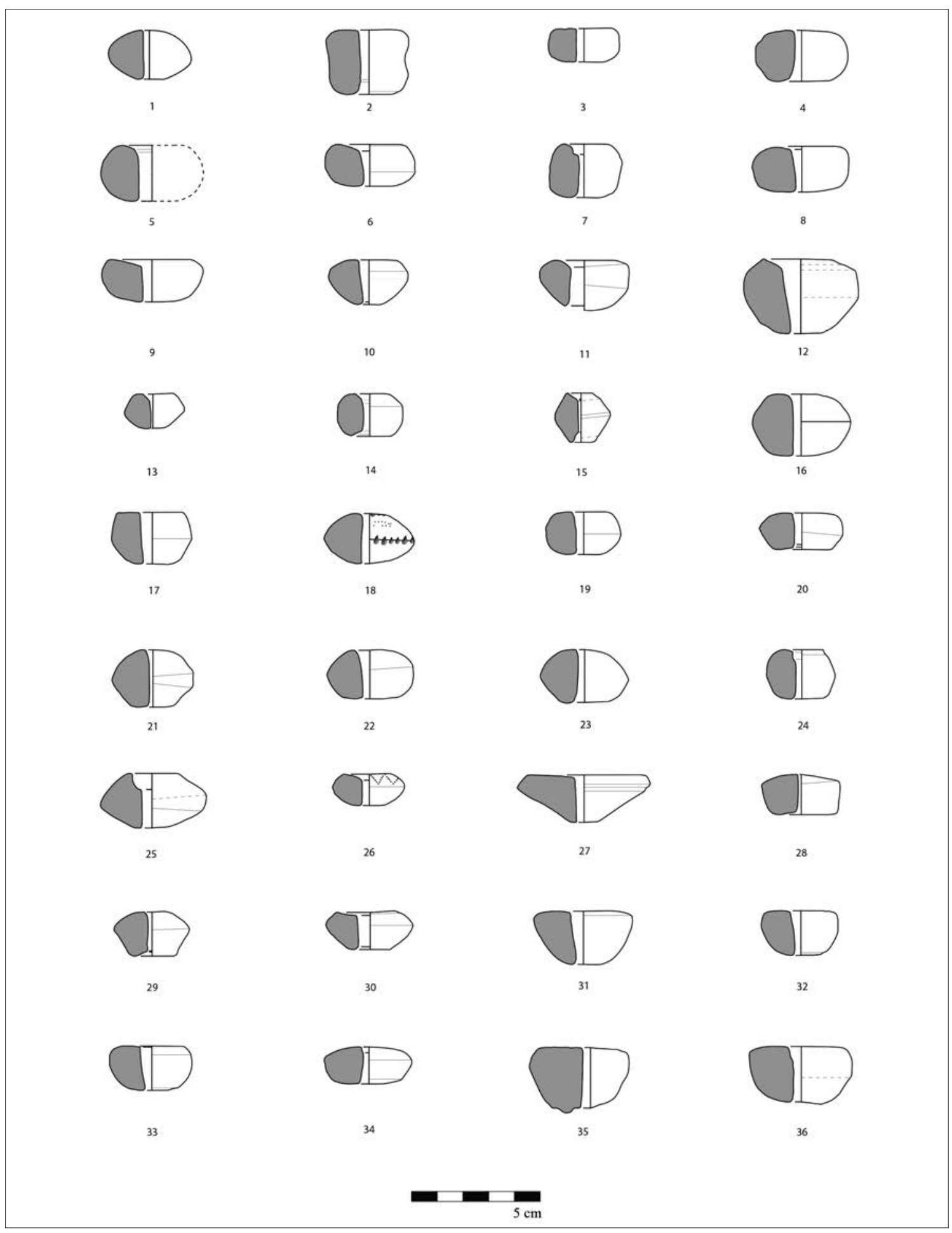

Fig. 2: Fusayolas de la necrópolis de OSM. 


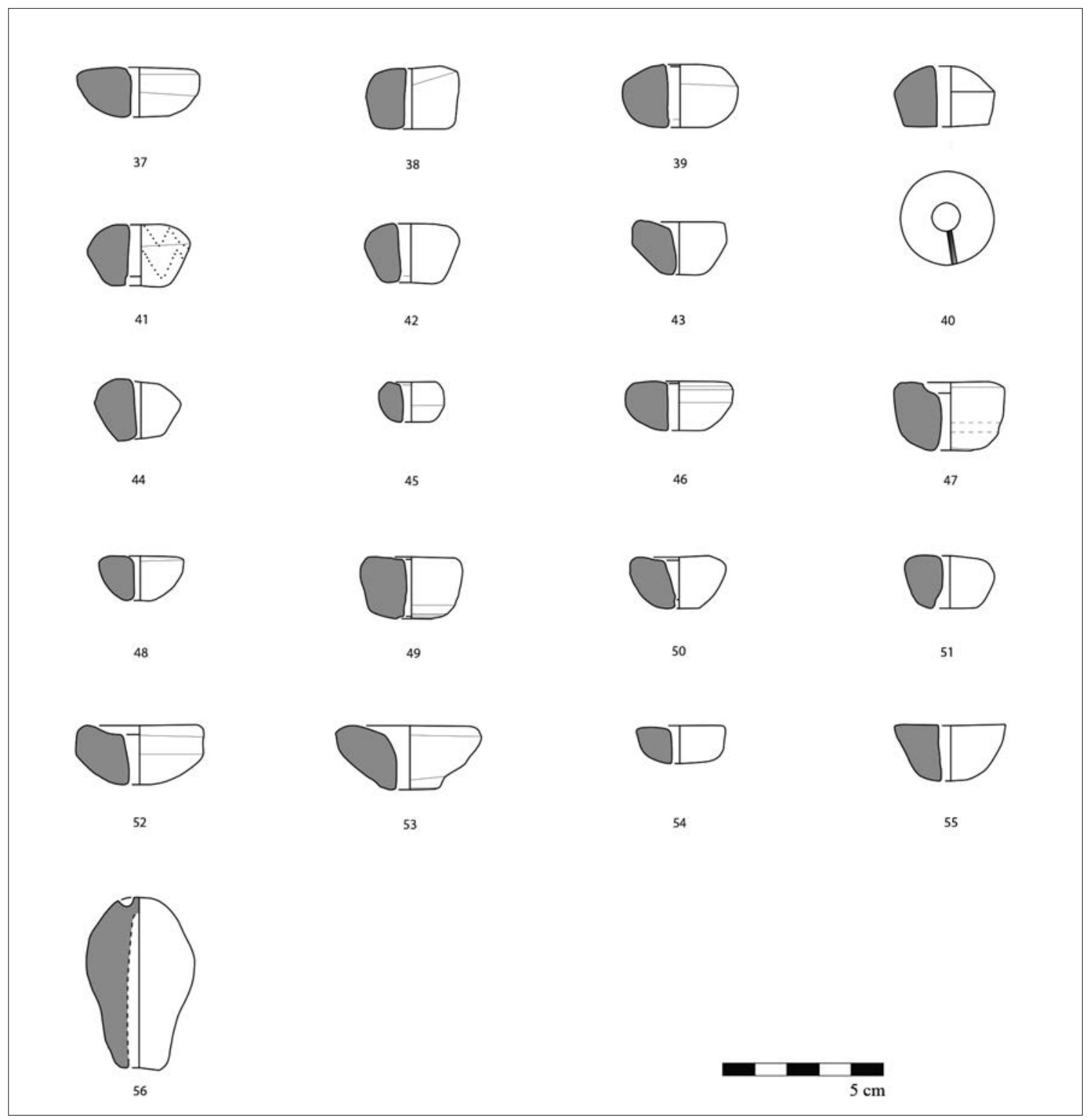

Fig. 3: Fusayolas de la necrópolis de OSM.

Grupo 1: arcillas pobres en carbonatos de calcio cocidas en ambiente oxidante, de coloración beige anaranjado a naranja vivo o marrón claro; estas pastas generalmente son compactas pero poco depuradas, y presentan inclusiones frecuentes, de pequeñas a medianas dimensiones, entre las cuales destacan las micas blancas (moscovita) y las arenas de cuarzo, acompañadas en ocasiones de nodos de calcita y/o de plagioclasas.
Grupo 2: arcillas relativamente ricas en carbonatos de calcio cocidas en ambiente predominantemente reductor, de coloración entre el blanco grisáceo y el gris claro; estas pastas, por lo general, son compactas y bien depuradas, y presentan inclusiones no muy frecuentes y de muy pequeñas a pequeñas dimensiones, en particular micas blancas, arenas de cuarzo y puntualmente nodos de calcita. 


\begin{tabular}{|c|c|c|c|c|c|c|c|}
\hline \# Inventario & Morfología* & Tipo & Grupo & Alt. & D. $\mathbf{M}$. & P. $(\mathrm{g})$ & Decoración \\
\hline 1 & $\mathrm{~K} 3 \mathrm{~K} 1$ & $\mathrm{~A} 1$ & 3 & 1,9 & 3,2 & 15 & \\
\hline 2 & K2K2 & B1 & 2 & 2,5 & 3,2 & 26 & \\
\hline 3 & $\mathrm{~K} 2$ & $\mathrm{Bl}$ & 1 & 1,3 & 2,7 & 13 & \\
\hline 4 & $\mathrm{~K} 3 \mathrm{~K} 2 \mathrm{C} 1$ & $\mathrm{Bl}$ & 1 & 2 & 3,6 & 21 & \\
\hline 5 & $\mathrm{~K} 2$ & $\mathrm{~A} 2$ & 2 & 2,2 & 4 & 28 & \\
\hline 6 & $\mathrm{~K} 2$ & B2 & 1 & 1,7 & 3,9 & 18 & \\
\hline 7 & P3P2 & $\mathrm{B} 2$ & 2 & 2,1 & 2,8 & 20 & \\
\hline 8 & K2 & $\mathrm{B} 2$ & 1 & 1,8 & 3,7 & 28 & \\
\hline 9 & P3Kl & $\mathrm{B} 2$ & 2 & 1,6 & 4 & 29 & \\
\hline 10 & P3P2K1 & Dbl & 3 & 1,7 & 3,1 & 14 & \\
\hline 11 & $\mathrm{~K} 2 \mathrm{~K} 1$ & Db2 & 2 & 2 & 3,5 & 11 & \\
\hline 12 & C3K2P1 & Db2 & 3 & 2,9 & 4,5 & 56 & \\
\hline 13 & P3Pl & Db2 & 3 & 1,3 & 2,3 & 8 & \\
\hline 14 & P3K1 & Db3 & 1 & 1,6 & 2,5 & 14 & \\
\hline 15 & P3P1 & Db3 & 1 & 1,9 & 2,2 & 8 & \\
\hline 16 & K3KI & Dcl & 1 & 2,4 & 3,7 & 31 & \\
\hline 17 & P3K1 & Dcl & 2 & 2 & 3,1 & 26 & \\
\hline 18 & K3Kl & Del & 1 & 1,9 & 3,5 & 21 & Impresa \\
\hline 19 & $\mathrm{~K} 3 \mathrm{~K} 1$ & Dc1 & 3 & 1,7 & 2,9 & 14 & \\
\hline 20 & K3P1 & Dc1 & 2 & 1,5 & 3,2 & 17 & \\
\hline 21 & $\mathrm{~K} 2 \mathrm{C} 1$ & $\mathrm{Db} 1 / \mathrm{Dc} 1$ & 1 & 2,2 & 3,1 & 18 & \\
\hline 22 & K3K I & Dcl & 1 & 1,9 & 3,4 & 20 & \\
\hline 23 & K3K1 & Dc1 & 1 & 2 & 3,4 & 23 & \\
\hline 24 & P3P1 & Dc2 & 2 & 2 & 2,7 & 10 & \\
\hline 25 & P3K1 & $\mathrm{Dc} 2$ & 1 & 2,1 & 4,2 & 30 & \\
\hline 26 & K3K1 & Dc2 & 1 & 1,2 & 2,7 & 9 & Puntillada \\
\hline 27 & P3P1 & Eal & 2 & 1,8 & 5,2 & 44 & \\
\hline 28 & K3Pl & Eal & 3 & 1,5 & 3,1 & 15 & \\
\hline 29 & $\mathrm{~K} 3 \mathrm{C} 1$ & $\mathrm{Ea} 3$ & 3 & 1,7 & 2,9 & 16 & \\
\hline 30 & P3P1 & $\mathrm{Ea} 3$ & 1 & 1,6 & 3,4 & 18 & \\
\hline 31 & K1 & Ecl & 1 & 2,1 & 3,8 & 33 & \\
\hline 32 & $\mathrm{P} 2 \mathrm{~K} 1$ & Ecl & 3 & 1,8 & 3 & 16 & \\
\hline 33 & P2K1 & $\mathrm{Ec1}$ & 2 & 1,7 & 3,2 & 21 & \\
\hline 34 & K3P1 & Ecl & 3 & 1,5 & 3,4 & 19 & \\
\hline 35 & K3Kl & Ecl & 3 & 2,5 & 3,9 & 23 & \\
\hline 36 & K2Kl & Ecl & 3 & 2,2 & 4 & 24 & \\
\hline 37 & K2KI & Ecl & 3 & 1,5 & 3,8 & 20 & \\
\hline 38 & K3K1 & Ecl & 1 & 2 & 2,8 & 24 & \\
\hline 39 & P3K1 & $\mathrm{Ecl}$ & 1 & 1,9 & 3,6 & 34 & \\
\hline 40 & P3K1 & Ecl & 3 & 1,8 & 3,2 & 21 & \\
\hline 41 & K3PI & Ecl & 1 & 2 & 3,2 & 18 & Puntillada \\
\hline 42 & $\mathrm{~K} 3 \mathrm{Pl}$ & Ecl & 1 & 1,9 & 3 & 16 & \\
\hline 43 & P3P1 & Ecl & 2 & 1,7 & 2,9 & 16 & \\
\hline 44 & K3PI & Ecl & 1 & 2 & 2,7 & 8 & \\
\hline 45 & K3P1 & $E c 2$ & 2 & 1,3 & 2,1 & 8 & \\
\hline 46 & $\mathrm{P} 2 \mathrm{~K} 1$ & $\mathrm{Ec} 2$ & 1 & 1,6 & 3,3 & 18 & \\
\hline 47 & K1 & Ec2 & 3 & 2,2 & 3,5 & 24 & \\
\hline 48 & K1 & $\mathrm{Ec2}$ & 1 & 1,4 & 2,6 & 10 & \\
\hline 49 & K1 & Ec3 & 2 & 1,8 & 3,2 & 23 & \\
\hline 50 & $\mathrm{Kl}$ & Ec3 & 1 & 1,6 & 3 & 17 & \\
\hline 51 & K3PI & Ec3 & 2 & 1,6 & 2,8 & 18 & \\
\hline 52 & $\mathrm{C} 2 \mathrm{~K} 1$ & $\mathrm{Fc2}$ & 2 & 2,8 & 4 & 32 & \\
\hline 53 & $\mathrm{C} 2 \mathrm{Kl}$ & $\mathrm{Fc} 2$ & 3 & 2 & 4,5 & 30 & \\
\hline 54 & $\mathrm{~K} 1$ & $\mathrm{H1}$ & 1 & 1,2 & 2,8 & 12 & \\
\hline 55 & E2 & $\mathrm{Hl}$ & 2 & 1,7 & 3,5 & 23 & \\
\hline 56 & $*$ & $*$ & 2 & 5,4 & 3,4 & 43 & \\
\hline
\end{tabular}

Fig. 4: Descripción general de las fusayolas de OSM. 
Grupo 3: arcillas pobres en carbonatos de calcio que han sido objeto de cocciones irregulares u oxidantes, resultando en piezas de coloración marrón a marrón grisáceo; las pastas de este grupo son poco compactas y muy poco depuradas, $\mathrm{y}$ presentan inclusiones frecuentes, de pequeñas a medianas dimensiones, entre las cuales se cuentan arenas de cuarzo, micas blancas, plagioclasas y nodos de calcita.

En cuanto a la representatividad de estos grupos en el conjunto (fig. 5), cabría señalar que las piezas pertenecientes al Grupo 1 son claramente predominantes, sumando un total de 25 ejemplares $(43,85 \%$ del total). Estas piezas, cuya pasta es muy similar a la de las producciones vasculares mayoritarias en el yacimiento, pueden interpretarse sin dificultad como productos locales.

El Grupo 2, en cambio, suma un total de 17 ejemplares $(29,83 \%)$ que presentan fuertes afinidades con algunas de las producciones de cerámica gris del yacimiento, lo cual parece apuntar hacia una producción igualmente local. Finalmente, el Grupo 3, que parece representar una producción también local pero de cariz bastante menos cuidado, suma un total de 15 ejemplares $(26,32 \%)$.

En cuanto al tratamiento de las superficies, la mayoría de las piezas no presentan un tipo particular de acabado. Debe hacerse hincapié, sin embargo, en la presencia de un conjunto de piezas con superficies bien alisadas o incluso pulidas compuesto por 13 ejemplares $(22,8 \%$ del conjunto total); este tratamiento se ha documentado sobre todo en piezas de los Grupos 1 (seis ejemplares) y 2 (cinco ejemplares), pero se ha registrado también puntualmente en piezas de producción menos cuidada del Grupo 3 (dos ejemplares).

Debe por otro lado señalarse la presencia en el conjunto estudiado de tres piezas cuyas superficies presentan motivos decorativos (5,3\% del conjunto total). Esta baja incidencia de la decoración parece algo sorprendente, teniendo en consideración la profusión decorativa registrada en otros conjuntos de referencia del SO peninsular (Berrocal-Rangel et al. 1994: 219-226; Berrocal-Rangel 2003: fig. 9; Pereira 2013), pero cuadra bien con el aspecto generalmente poco elaborado de las piezas estudiadas.

Por otro lado, debe tenerse en cuenta que esos otros conjuntos provienen de contextos de uso distintos, de naturaleza no funeraria, lo cual podría influir en la incidencia de elementos decorativos.

Dos de las piezas decoradas de OSM presentan decoración puntillada en forma de línea quebrada, en un caso sencilla y en el otro doble. El tercer ejemplar, por otro lado, presenta una decoración muy irregular obtenida por

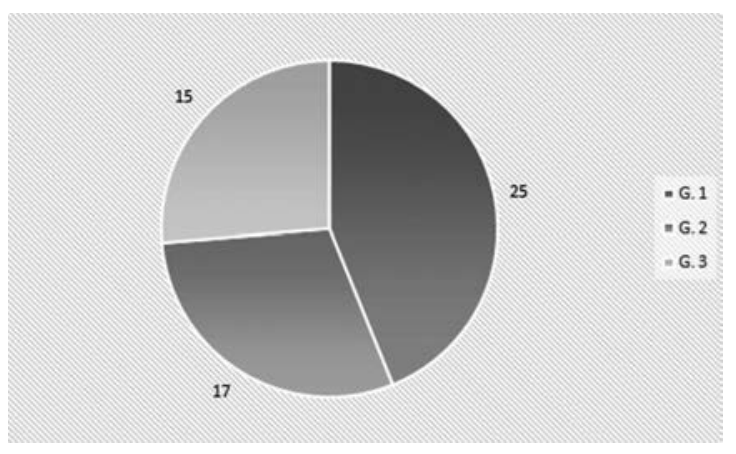

Fig. 5: Distribución de las fusayolas de OSM por grupos productivos.

impresión con un elemento tubular formando motivos en lágrima dispuestos en un arco incompleto sobre la carena de la fusayola, a los cuales se suman otros motivos idénticos dispuestos de forma aparentemente aleatoria en la faceta superior de la pieza; estos motivos se encuentran acompañados por puntillados poco profundos realizados también de forma aleatoria.

\section{ANÁLISIS MORFOLÓGICO Y ESTADÍSTICO}

La heterogeneidad registrada en el apartado anterior a propósito de los detalles productivos de estas piezas se extiende igualmente a su conformación tipológica. El conjunto presenta, en efecto, un aspecto global muy poco normalizado, hecho que podría resultar de su producción predominantemente manual.

Por esta razón, la ordenación tipológica del material estudiado constituyó una tarea compleja. Sin embargo, se han podido organizar las piezas que componen este conjunto en función de la tipología propuesta por Z. Castro Curel (1980) y ampliada por M. L. de Sus (1985) y por T. R. Pereira (2013).

Por otro lado, a esa ordenación tipológica básica se ha añadido en la Tabla descriptiva (fig. 4) la descomposición de la morfología de las piezas en cuerpos geométricos básicos según el código desarrollado por L. BerrocalRangel y sus colaboradores (Berrocal-Rangel et al. 1994; Berrocal-Rangel 2003), ya que esa descripción permite reflejar de forma más detallada la variabilidad morfológica existente incluso dentro de una misma variante formal.

La ordenación tipológica obtenida (fig. 6) revela una clara predominancia de las formas bitroncocónicas, en especial las fusayolas bitroncocónicas asimétricas (Tipo E), que suman 25 piezas $(44,6 \%$ del total). Dentro de este 


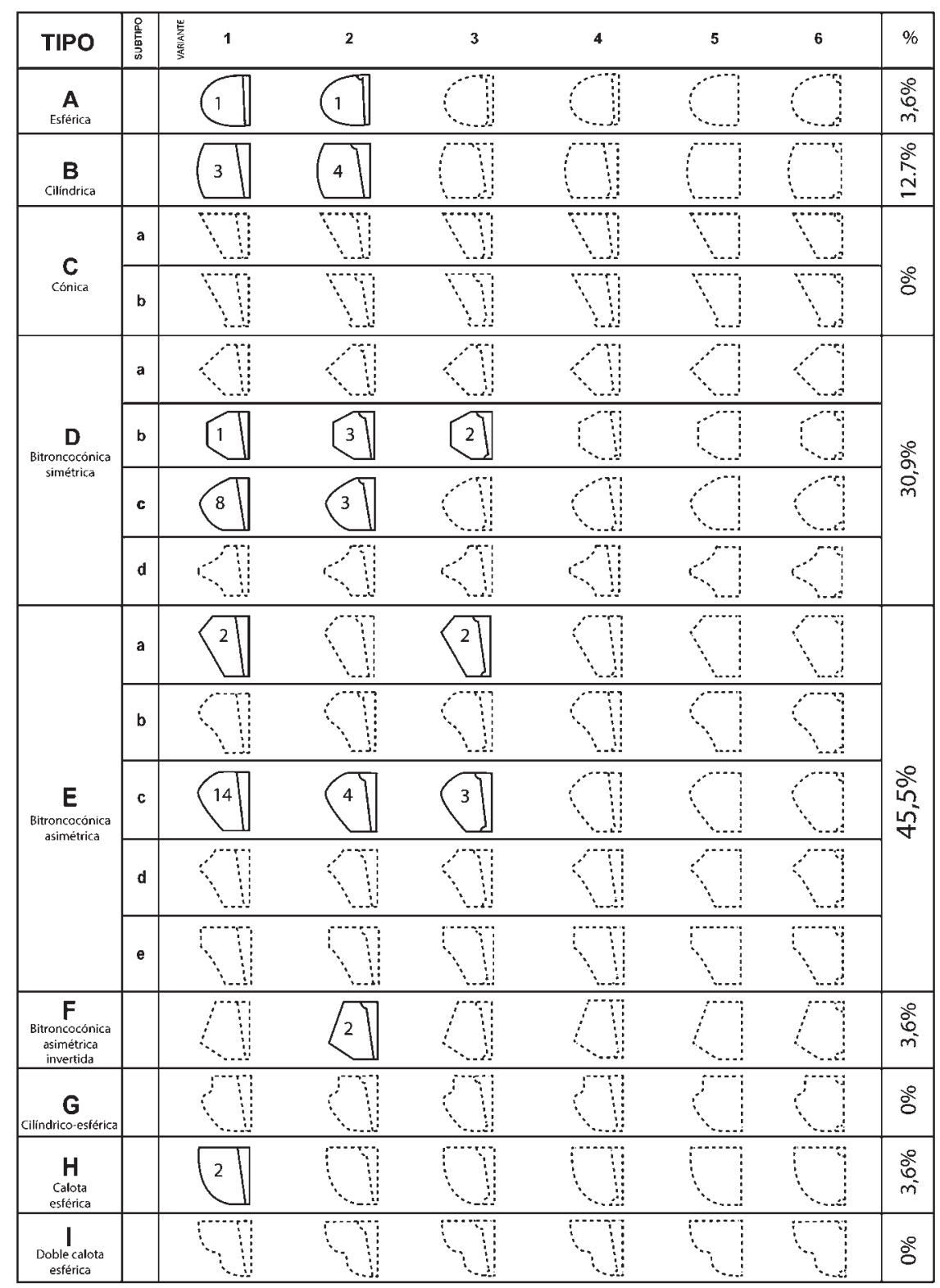

Fig. 6: Tipología de las fusayolas de OSM.

grupo, el subtipo más común, con 21 ejemplares, presenta caras convexas (Subtipo Ec), mientras que las caras de las cuatro piezas restantes son rectas (Subtipo Ea) (fig. 7).

Las fusayolas bitroncocónicas simétricas (Grupo D) son también frecuentes, sumando 18 ejemplares $(32,1 \%)$. Las piezas de este grupo se pueden también subdividir en función del aspecto de sus caras, predominando una vez más el subtipo con caras convexas (Subtipo Dc: 12 ejemplares) sobre el de caras rectas (Subtipo Db: seis ejemplares).
Las piezas de configuración cilíndrica del Grupo B se encuentran también bien representadas, con ocho ejemplares (14,2\% del total). Se registran además, de forma residual, ejemplares de morfología bitroncocónica asimétrica invertida (Grupo F: dos ejemplares, 3,6\%), en casquete esférico (Forma H: dos ejemplares, 3,6\%) y en esfera (Grupo A: un ejemplar, 1,8\%).

Pasando a la cuestión de la configuración del orificio central de las piezas estudiadas se puede señalar la 
Fig. 7: Representatividad de los distintos tipos de fusayolas en el conjunto de OSM.

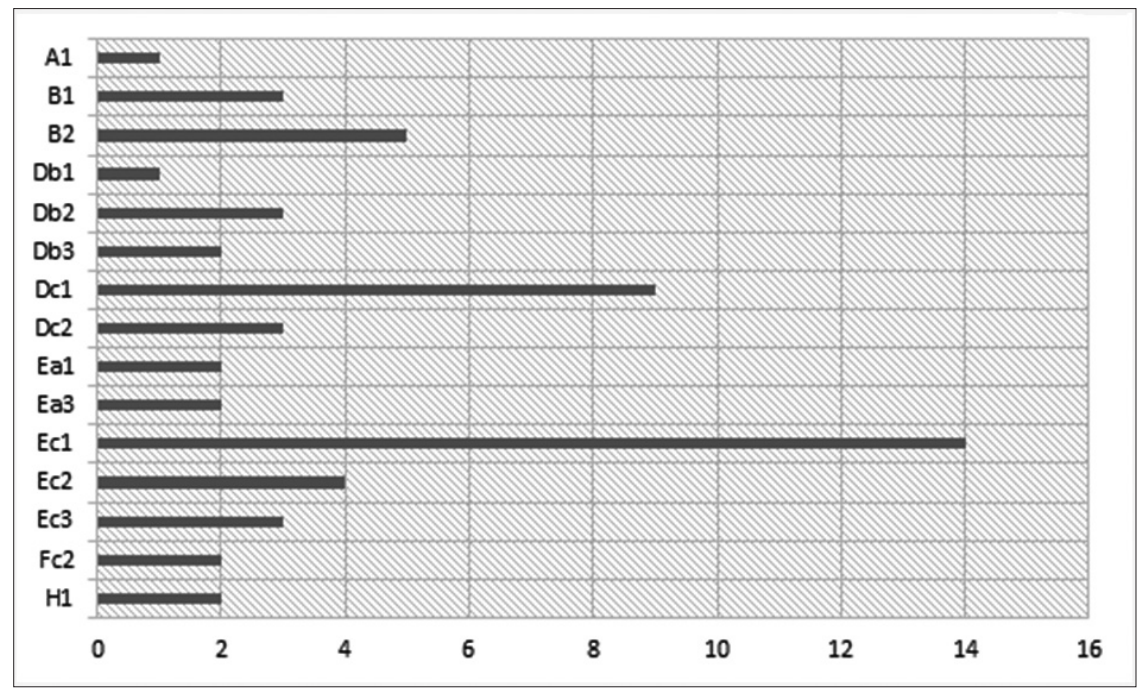

predominancia de orificios de perfil regular o ligeramente divergente -es decir, la variante 1 de los distintos subtipos antes comentados- que se han podido documentar en un total de 32 piezas $(57,1 \%$ del conjunto), aunque también se encuentren bien representadas las variantes con perfil escalonado en la extremidad superior (variante 2: 17 ejemplares, 30,4\%) o en ambas extremidades (variante 3: siete ejemplares, 12,5\%).

Este patrón morfológico general se puede considerar muy similar al que se ha registrado en otros conjuntos de referencia. De hecho, las fusayolas bitroncocónicas son por lo general mayoritarias en los contextos de la Edad del Hierro, sumando $66,6 \%$ del conjunto de Ullastret $(37,8 \%$ del Tipo D y 28,8\% del Tipo E) (Castro Curel 1980: 140), $87,5 \%$ en el de La Creueta (Tipo D: $25 \%$; Tipo E: 62,5\%) (ibidem), 68,2\% en el de Castell de la Fosca (Tipo D: 13,7\%; Tipo E: 54,5\%) (ibidem), 86,7\% en el de Castellares (Tipo D: 25,3\%; Tipo E: 61,4\%) (de Sus 1986), 62,4\% en el del Altar A del Castrejón de Capote (Berrocal-Rangel et al. 1994), 63,25\% en el de Cancho Roano (BerrocalRangel 2003) y 68,8\% en el de Cabeça de Vaiamonte (Tipo D: 18,5\%; Tipo E: 50,3\%) (Pereira 2013).

El porcentaje comparativamente elevado de piezas de tendencia cilíndrica del Tipo B representa, sin embargo, una particularidad de la necrópolis de Alcácer do Sal, aunque los valores de este yacimiento se puedan comparar con los de Cancho Roano (10,78\%: Berrocal-Rangel 2003) y de Vaiamonte (7\%: Pereira 2013).

Finalmente, cabría señalar que la reducida representación de las piezas de morfología bitroncocónica invertida
(Tipo F) y en casquete esférico (Tipos A y H) se encuadra perfectamente en el panorama registrado en los distintos conjuntos de referencia antes mencionados.

Mención aparte en este apartado merece el presumible rocadero anteriormente comentado. Esta pieza presenta una morfología piriforme y dimensiones bastante considerables (10,3 cm de altura para un diámetro máximo de $3,4 \mathrm{~cm}$ ), habiéndose realizado en su eje vertical una profunda perforación que secciona prácticamente toda la pieza; en la extremidad opuesta se ha realizado igualmente una perforación, descentrada con respecto a la anterior, quizás un intento poco exitoso de completar el canal central conformado por la perforación antes comentada.

Aparte de la cuestión de su morfología general, otro aspecto indispensable del análisis de las fusayolas concierne a sus dimensiones, relacionadas de forma muy directa con cuestiones de orden funcional. Así, y de acuerdo con los criterios establecidos en los estudios de referencia ya citados (Castro Curel 1980; de Sus 1986; Berrocal-Rangel et al. 1994; Berrocal-Rangel 2003; Pereira 2013), las piezas en estudio se han analizado estadísticamente en función a tres variables fundamentales: su altura, su diámetro y su peso (figs. 8 y 9).

En cuanto a la primera de estas variables, las fusayolas de la necrópolis de OSM presentan alturas entre los 1,2 y los $2,9 \mathrm{~cm}$, siendo la media de $1,9 \mathrm{~cm}$. Las piezas se distribuyen a lo largo de este intervalo de forma homogénea, con lo cual no se aprecian módulos de altura específicos y diferenciados (fig. 8, A). 


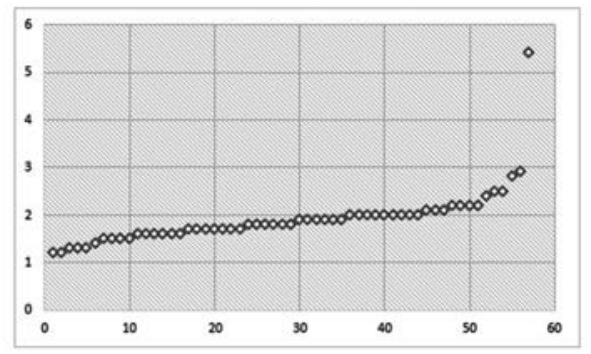

A

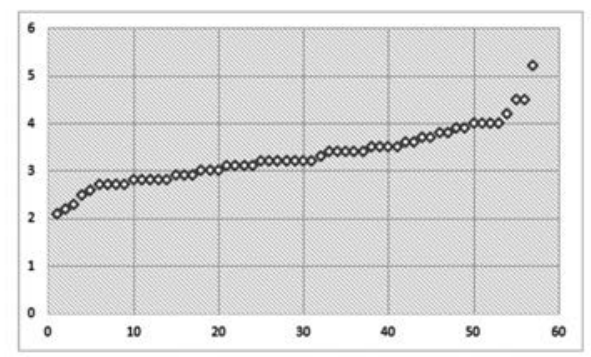

C

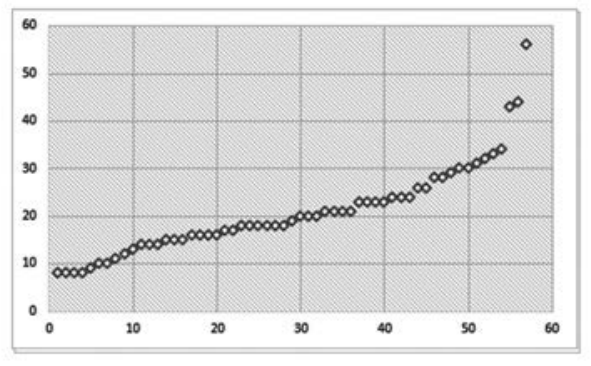

E

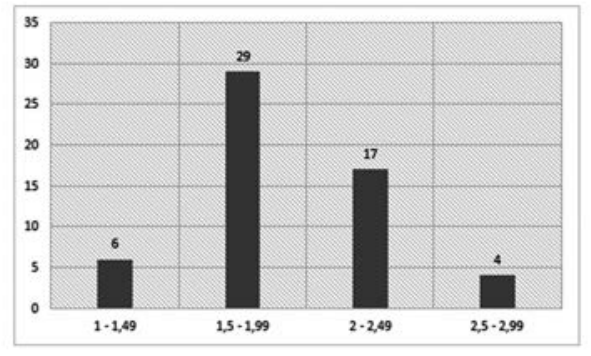

B

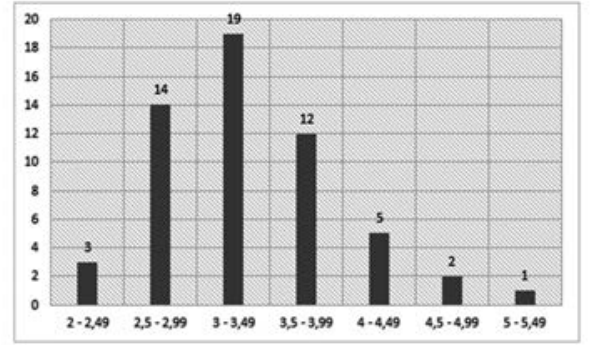

D

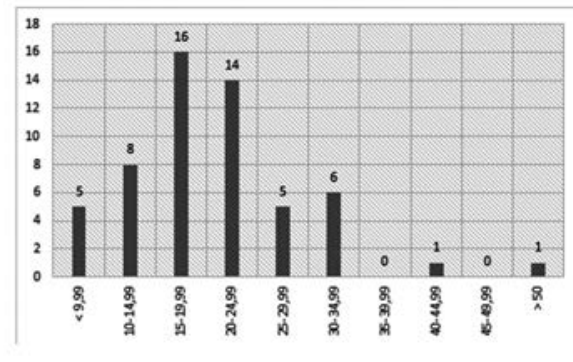

F

Fig. 8: Atributos morfológicos de las fusayolas de OSM: A: distribución por altura; B: distribución por intervalos de altura; C: distribución por diámetro; D: distribución por intervalos de diámetro; E: distribución por peso; F: distribución por intervalos de peso.

Puede sin embargo señalarse una concentración significativa en los intervalos de 1,5 a $1,9 \mathrm{~cm}$ (29 ejemplares, $51,8 \%$ del total) y de 2 a $2,4 \mathrm{~cm}(17$ ejemplares, $30,4 \%)$; los ejemplares con valores inferiores, de 1,2 a $1,4 \mathrm{~cm}$ (seis ejemplares, $10,7 \%$ ), y superiores, entre $2,5 \mathrm{y}$ $2,9 \mathrm{~cm}$ (cuatro ejemplares, $7,1 \%$ ) son bastante menos representativos (fig. 8, B).

Los diámetros de las piezas estudiadas, por otro lado, se distribuyen entre los 2,1 y los 5,2 cm (media de 3,3 cm), igualmente de forma muy uniforme, sin que parezca existir cualquier módulo específico predeterminado (fig. 8, C).
No obstante, también aquí se registran concentraciones significativas, en este caso entre los 2,5 y los $2,9 \mathrm{~cm}$ (14 ejemplares, $25 \%$ ), entre los 3 y los $3,4 \mathrm{~cm}$ (19 ejemplares, $33,9 \%$ ) y entre los 3,5 y $\operatorname{los} 3,9 \mathrm{~cm}$ (12 ejemplares, $21,4 \%)$. Siguen, en cuanto a frecuencia absoluta de ejemplares, los intervalos entre los 4 y $\operatorname{los} 4,4 \mathrm{~cm}$ (cinco ejemplares, $8,9 \%$ ), entre los 2,1 y los $2,4 \mathrm{~cm}$ (tres ejemplares, 5,4\%) y entre los $4,5 \mathrm{y}$ los 4,9 cm (dos ejemplares, $3,6 \%$ ); el intervalo entre los 5 y los $5,2 \mathrm{~cm}$ cuenta con un único ejemplar $(1,8 \%)$ (fig. $8, \mathrm{D})$. 


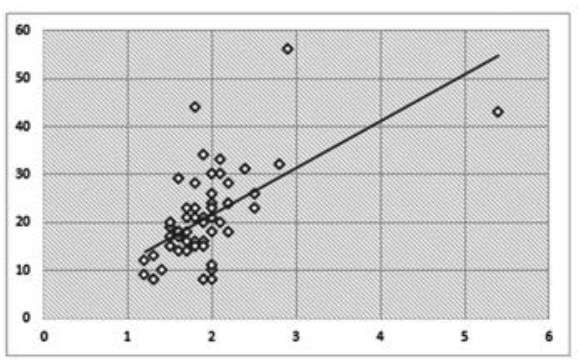

A

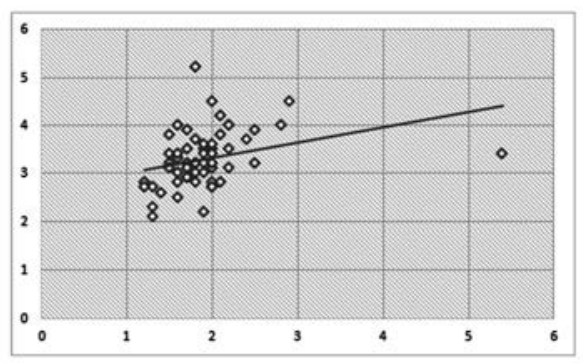

C

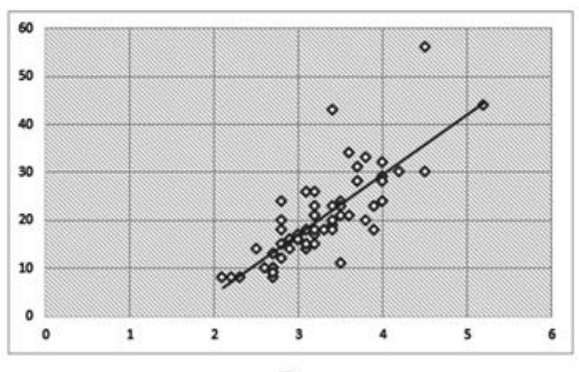

$\mathbf{E}$

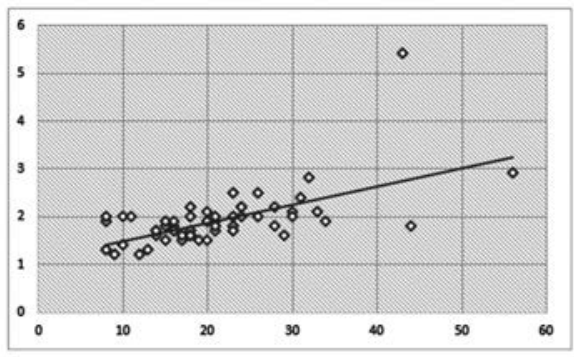

B

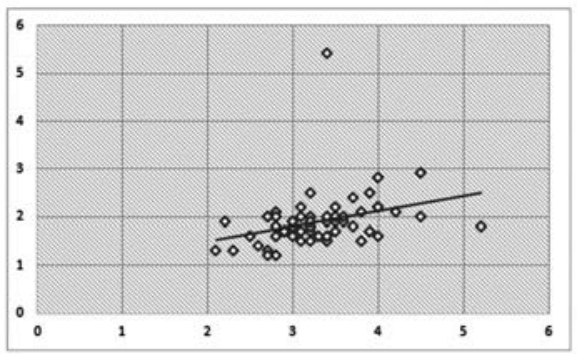

D

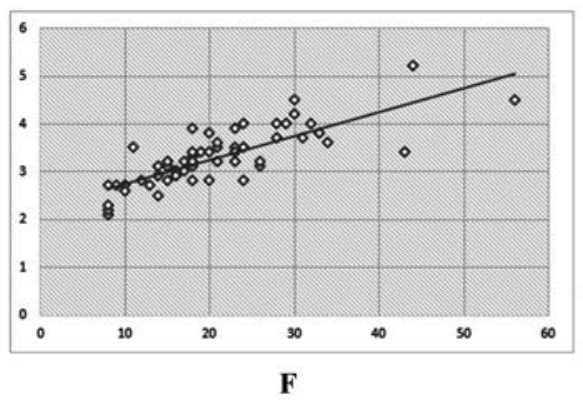

Fig. 9: Correlación entre los atributos morfológicos de las fusayolas de OSM (rectas de regresión): A: Altura/Peso; B: Peso/Altura; C: Altura/ Diámetro; D: Diámetro/Altura; E: Diámetro/Peso; F: Peso/Diámetro.

Esta distribución de los diámetros de las piezas del OSM se puede considerar paralela a la que se documentó en el material del Altar A del Castrejón de Capote (Berrocal-Rangel et al. 1994), en el cual predominan los diámetros entre los 2,9 y los 3,49 cm, que suman unos 57,4\% del conjunto total, o en el de Cancho Roano (Berrocal-Rangel 2003), donde el intervalo estadísticamente dominante era el de 2 a 3,2 cm de diámetro.

Finalmente, en lo que toca a sus pesos, se vuelve a repetir la curva de distribución más o menos continuada registrada para las medidas anteriores, lo cual, en principio, parece excluir una posible utilización de estas piezas como ponderales (fig. 8, E). En este caso específico, los valores oscilan entre los 8 y los $56 \mathrm{~g}$, siendo la media de 20,4 g.

Los intervalos de peso más bien representados se encuentran entre los 15 y los $19,9 \mathrm{~g}$, con 16 ejemplares (28,6\% del total), y entre los 20 y los $24,9 \mathrm{~g}$, con 14 ejemplares (25\%); siguen, en cuanto a frecuencia absoluta de ejemplares, los intervalos de 10 a $14,9 \mathrm{~g}$ (ocho ejemplares, 14,3\%), de 30 a 34,9 g (seis ejemplares, $10,7 \%$ ), entre los $30 \mathrm{y}$ los $34,9 \mathrm{~g}$ (cinco ejemplares, 
$8,9 \%$ ) y por debajo de los $10 \mathrm{~g}$ (cinco ejemplares, $8,9 \%)$. Los valores entre los 40 y los $44,9 \mathrm{~g}$ y por encima de los $50 \mathrm{~g}$, con un ejemplar cada uno $(1,8 \%)$ pueden considerarse residuales (fig. 8, F).

Este panorama coincide de forma bastante clara con el que se ha podido documentar en otros conjuntos, como el de Castellares, donde el intervalo de 15 a 20 g es mayoritario, sumando 22\% del total (de Sus 1986), el de Cabeça de Vaiamonte, donde el mismo intervalo es predominante, reuniendo 22,1\% del conjunto (Pereira 2013) o incluso el de Cancho Roano, donde el intervalo entre los 12 y los 21,9 g, sin llegar a ser el más representativo, suma aun así unos 30,05\% del conjunto total (BerrocalRangel 2003).

Con base a estas medidas he tratado de buscar los factores que han determinado la configuración específica de estas piezas utilizando para ello métodos elementales de análisis estadístico. Así, puede señalarse que los valores de la covarianza entre la altura y el diámetro son bastante bajos, con un factor de 0,14 , siendo su cociente de correlación muy reducido $(0,4)$; la relación entre la altura y el peso es un poco más expresiva, pero aun así bastante débil, presentando una covarianza de 3,61 y un cociente de correlación de 0,61 .

Sin embargo, sí parece existir una fuerte relación entre el diámetro y el peso de estas piezas, registrándose una covarianza de 4,24 y un cociente de correlación de 0,82 . Este hecho no resulta demasiado sorprendente, ya que estas piezas desempeñarían una función -la de propiciar y mantener el movimiento giratorio del huso- de cara a la cual la masa y la circunferencia serían bastante más determinantes que la altura ( $c f$. Rahmstorf 2015: 5).

La observación de las rectas de regresión obtenidas con base en estas variables parece reforzar esta impresión (fig. 9): en todos los casos en que la altura se ha introducido como variable causal el resultado obtenido se caracteriza por una gran dispersión de los valores (fig. 9, A y C).

A la inversa, los gráficos en que el diámetro (fig. 9, D y E) y sobre todo el peso (fig. 9, B y F) se han tomado como variables independientes revelan una organización más o menos clara de los datos en torno a una recta bien definida, confirmando la importancia del peso y, hasta cierto punto, del diámetro en la configuración de las fusayolas del OSM.

Esta situación es similar a la que se ha registrado para el conjunto de Cancho Roano (Berrocal-Rangel 2003), aunque en el yacimiento extremeño la importancia de la variable diámetro esté más bien documentada que en el conjunto aquí estudiado, donde el peso parece ser el criterio principal en la producción de estos elementos.

\section{LAS FUSAYOLAS EN CONTEXTOS FUNERARIOS DE LA EDAD DEL HIERRO: ALGUNAS NOTAS SOBRE FUNCIONALIDAD Y SIMBOLISMO}

Tras el análisis productivo y morfológico de las fusayolas de la necrópolis del OSM que he intentado realizar en las páginas anteriores abordaré a continuación el significado cultural y social de dichos elementos en este yacimiento. Esta tarea, dificultada por la falta de contextos específicos para el material analizado, puede sin embargo afrontarse, aunque de forma exploratoria, con base en una metodología comparativa que parece relevante para comprender el significado del conjunto estudiado.

Cabría antes señalar que, a pesar de estar presentes al menos desde el Calcolítico (Cardito 1996), las fusayolas no se documentan en número significativo en la península Ibérica hasta la Edad del Bronce, período en que se convierten en un elemento relativamente frecuente, al menos en el mundo argárico del SE (López Mira 1995; Ruiz de Haro 2012: 137-139; para el occidente peninsular, v. tb Luís 2014), esto a pesar de que este tipo de piezas sea frecuente en el Oriente Próximo ya desde el Neolítico Antiguo y en el Mediterráneo desde al menos el Neolítico Final/ Calcolítico (Castro 1980: 128; Barber 1991; Ruiz de Haro 2012; Rahmstorf 2015: 2-6).

Sin embargo, el período de máxima difusión de las fusayolas y su correspondiente técnica de hilado parece coincidir ya con la Edad del Hierro (Castro 1980: 132; cf. tb. Barber 1991: 55); en particular, resulta llamativa la aparición de conjuntos muy significativos de piezas de este tipo en contextos de la II Edad del Hierro (Castro 1980; de Sus 1986; Berrocal-Rangel et al. 1994; Sánchez Gómez 2002; Guérin 2003; Pereira 2013) que evidencian su gran desarrollo durante la segunda mitad del primer milenio a.n.e.

En el caso de la necrópolis de OSM, y como he comentado anteriormente, la presencia de fusayolas integrando los ajuares funerarios parece anteceder ese momento de mayor difusión, remontando posiblemente al s. VI a.n.e., si no a la centuria anterior, cronología que vendría refrendada por su asociación a las más antiguas tipologías sepulcrales de la necrópolis, y en particular a las sepulturas del Tipo $4^{\circ}$ de V. Correia (1928 [1971]). 
El depósito de fusayolas en contextos funerarios no es muy común durante la Primera Edad del Hierro del SO peninsular, aunque se pueda señalar la presencia de una pieza de este tipo en un entorno geográfico no muy lejano, en la Sepultura 3 de la necrópolis de Pardieiro (Odemira) (Beirão 1990: 117).

La presencia de este tipo de elementos en contextos de la II Edad del Hierro, que como he tenido ocasión de comentar arriba, se encuentra perfectamente documentada en el OSM, constituye al revés un hecho bastante más extendido. Así, y en el mismo territorio portugués, cabría señalar por ejemplo los casos de las necrópolis de Quinta da Queimada (Lagos) (Calado y Gomes 2006: 177-178) y de Chaminé (Elvas) (Heleno 1951).

Sin embargo, el depósito de estos objetos en contextos sepulcrales ha conocido su máxima expresión en las necrópolis ibéricas del SE español. Se pueden citar, a título de ejemplo y sin pretensiones de exhaustividad, los ejemplos de las necrópolis de El Cigarralejo (Cuadrado 1987) y de Cabecico del Tesoro (Sánchez y Quesada 1992), en Murcia, de Cabezo Lucero en Alicante (Aranegui et al. 1993), de Baza en Granada (Presedo 1982), de Los Villares y de Hoya de Santa Ana en Albacete (Blánquez 1990) o de Pozo Moro, igualmente en Albacete (Alcalá-Zamora 2003), en las cuales se han exhumado conjuntos en ocasiones muy expresivos de fusayolas, asociados en muchos casos a otros elementos relacionados con la producción textil.

Tradicionalmente, la presencia de estos elementos en contextos funerarios se ha leído en clave de género, interpretándose estas piezas como propias de tumbas femeninas. Este tipo de lecturas, que han tenido reflejo también en la historiografía portuguesa (Beirão 1990: 117), han enfatizado el carácter femenino de la actividad textil, con lo cual la presencia de fusayolas en tumbas se ha interpretado como mero reflejo de su funcionalidad "práctica" primaria, sin que se haya reconocido o intentado explicar el sentido específico que estos elementos adquieren en el marco de los discursos funerarios ( $c f$. Rafel 2007; Ruiz de Haro 2012: 142).

Sin embargo, el avance de la investigación y, sobre todo, el número creciente de análisis antropológicos disponibles, sumados a nuevos ejercicios críticos fundados en el análisis estadístico de los ajuares funerarios y de sus asociaciones y potenciados por el desarrollo de la Arqueología Feminista y de Género española, han venido a demostrar que la asociación simplista entre fusayolas y tumbas femeninas no dispone de un soporte empírico real (Rafel 2007; Horn 2011: 175-181).
Tal no significa en absoluto que las fusayolas no tengan una fuerte asociación con la esfera feminina, hecho que sí parece demostrado en algunos contextos (Rísquez y García Luque 2012: 263-264). Sin embargo, esa asociación no parece suficiente para explicar la totalidad de los casos documentados en que estos elementos se han incorporado en los depósitos funerarios.

Ejemplos como el de El Cigarralejo, en que un 19\% de las tumbas con armas, tradicionalmente consideradas masculinas, contenían igualmente fusayolas u otros elementos relacionados con la producción textil (Rafel 2007: 123), o de Cabezo Lucero, en que un 73\% de las fusayolas exhumadas provenían también de tumbas con armas (Rafel 2007: 129) son particularmente expresivos, y ni siquiera constituyen casos aislados, ya que se les podrían sumar otros casos, como el del Cabecico del Tesoro, en que un $16 \%$ de las tumbas con armas contienen igualmente fusayolas entre sus ajuares (Sánchez y Quesada 1992: 372).

El análisis estadístico realizado por F. Horn en base a las tumbas ibéricas para las cuales se dispone de una identificación del sexo del difunto basada en análisis antropológicos fiables revela tendencias muy similares, habiéndose contabilizado 16 sepulturas masculinas con fusayolas pero solamente 15 con armas (Horn 2011: 178).

Considerados estos datos, la inadecuación de la explicación "de género" para la presencia de fusayolas en tumbas parece doble: por un lado, no toma en consideración el significado específico que estas piezas adquieren en contextos funerarios, limitándose a transponer para las piezas de las necrópolis su significado funcional habitual, y por otro no es compatible con los patrones de distribución por sexo observables en el registro arqueológico.

El intento de sortear esta última dificultad interpretando los individuos masculinos en cuyas sepulturas se han depositado fusayolas como propietarios de talleres textiles o como comerciantes especializados (Cabrera y Griñó 1986: 194) parece, desde mi punto de vista, un compromiso poco fundamentado, por lo que se deben buscar explicaciones alternativas para la presencia de estas piezas en el registro funerario.

Por otro lado, la necesidad de claves alternativas de lectura para el análisis de este tipo de material parece también muy evidente si consideramos que algunas de las mayores concentraciones de fusayolas documentadas en el SO peninsular provienen de contextos con una evidente carga religiosa asociada, tales como Cancho Roano 
(Berrocal-Rangel 2003), el Altar A del Castrejón de Capote (Berrocal-Rangel et al. 1994) o incluso Cabeça de Vaiamonte de acuerdo con una reciente reinterpretación (Pereira 2013).

La presencia abundante de fusayolas en contextos religiosos no es, además, exclusiva del SO, constituyendo un fenómeno bien documentado también en el mundo ibérico del E y del SE peninsulares (Sánchez Gómez 2002; Guérin 2003: fig. 39; Vílchez 2015; cf. también Martínez Valle y Castellano 1997).

Esto no significa que las piezas halladas en estos yacimientos no hayan tenido una función productiva -la cual parece claramente demostrada, por ejemplo, en Cancho Roano (Berrocal-Rangel 2003: 255)-, a pesar de que en algunos contextos sí se hayan registrado piezas cuya morfología parece incompatible con su uso habitual ( $c f$. Berrocal-Rangel 2003: 237; Pereira 2013).

La concentración de fusayolas en contextos religiosos y funerarios parece así apuntar a una explicación de tipo simbólico, como ya se ha sugerido en más de una ocasión (Lucas Pellicer 1992; Izquierdo 2001: 299), habiéndose señalado sobre todo el papel de las Moirai griegas, divinidades relacionadas con el destino que se han concebido, al menos desde Homero y Hesíodo ( $c f$. Dietrich 1962), como hilanderas que manejan la vida de los mortales como un hilo, hilándola (nacimiento), midiéndola (vida) y cortándola (muerte) ( $c f$. Greene 1944; de Angelis 1992; Giannoulis 2010; Pirenne-Delforge y Pironti 2011).

Aunque no sea posible en este contexto realizar un análisis detallado de los distintos significados mitológicos y metafóricos asociados con el hilado y la tejeduría (Alfaro 1986; Molina 1986; Scheid y Svenbro 1996; Olmos 2001; Nosch et al. 2016), me parece aun así pertinente señalar que lo que podríamos designar como la metáfora de la vida como hilo se detecta en contextos muy diversos en el mundo antiguo y alto-medieval, personificada por ejemplo en las ya referidas Moirai griegas (Giannoulis 2010; Pirenne-Delforge y Pironti 2011) pero también en sus homólogas romanas, las Parcae (Ballestra-Puech 1999; Dasen 2011), o incluso en las Nornas de la mitología nórdica (Lindow 2001: 243-245; Simek 2008: 236-237; Bek-Pedersen 2011).

Sin querer de ningún modo generalizar a partir de estos casos particulares, creo sin embargo plausible que esta metáfora, sencilla y potencialmente transversal desde el punto de vista cultual, haya estado presente en otros ámbitos, con mayor o menor desarrollo mitológico y escatológico. De hecho, las divinidades hilanderas del destino han sido ya consideradas como una herencia de un antiguo fondo cultural mediterráneo (Krause 1936; contra Dietrich 1962: 88-89). Por todo ello no me parece descabellado evocar esta metáfora para intentar una aproximación general al significado de las fusayolas depositadas en tumbas.

Por otro lado, y de forma no menos significativa, cabría recordar que el acto de hilar y el huso en cuanto objeto tienen, en determinados contextos culturales -entre ellos, al parecer, el de Grecia Antigua- una significación mágica muy presente en las creencias populares ( $c f$. Dietrich 1962). J. Frazer, en su seminal trabajo de mitología y simbología comparada, The Golden Bough, señala que la potencia mágica del huso podría interpretarse como una instancia de magia homeopática, ya que su movimiento de revolución podría provocar giros e inversiones indeseados, por ejemplo en las cosechas o incluso durante los embarazos (Frazer 1935: 102-103, apud Dietrich 1962), hecho que explicaría ciertas prohibiciones en el mundo greco-romano de portar un huso en público, como recoge por ejemplo Plinio el Viejo ${ }^{2}$.

Así, y aunque la existencia de una (o varias) divinidades hilanderas del destino anteriores a Homero no esté demostrada de forma clara, como señala B. C. Dietrich (1962: 88-89), el estudio de las creencias populares parece demostrar que la asociación ritual del acto de hilar con determinados momentos significativos del ciclo vital sí está bien documentada. En particular, su asociación con el acto de sembrar los campos y, sobre todo, con los nacimientos (idem: 92-93) parece señalar un nexo de conexión entre el hilado y la propiciación de la fertilidad y de la fecundidad.

Estas prácticas, que pertenecen al dominio de la magia y de la creencia popular, se asocian muy particularmente a la figura de Moira o de las Moirai, ya citada(s), que más allá de la elaboración poética homérica sobrevivirán en los cultos griegos como divinidades estrechamente relacionadas con el nacimiento (Dietrich 1962: 94-95). En otros contextos culturales, en particular próximo-orientales, este tipo de asociación mágica y simbólica se encuentra también relativamente bien documentada (Frazer 1935: 1113-1114; Dietrich 1962: 89).

En este contexto no puede tampoco dejar de señalarse la presencia, en algunos de los conjuntos de fusayolas de referencia del SO peninsular, de complejas y ricas gramáticas decorativas donde los elementos vegetales y astrales se encuentran muy bien representados, lo cual 
parece evidenciar también una asociación simbólica y quizás mágica entre el hilado y la manutención de la fertilidad y de la fecundidad.

Ahora bien, ambas líneas simbólicas -la asociación del huso y del hilado con el nacimiento, por un lado, y con el destino, por otro- pueden considerarse complementarias, ya que en las creencias populares que vengo comentando parece haberse desarrollado desde momentos relativamente tempranos una concepción de que el hilado que acompaña y propicia el nacimiento influye en el posterior desarrollo de la vida, creencia que parece haberse cristalizado tras incorporarse al discurso de la épica con los poemas homéricos (Dietrich 1962).

Así, y si es cierto que la transposición de estas concepciones mágicas y mitológicas para el contexto de la Edad del Hierro peninsular no puede realizarse sin muchas reservas y matices, la verdad es que estas claves de lectura parecen abrir un campo interpretativo más amplio para el estudio del depósito de los artefactos relacionados con el hilado y la producción textil en general en ámbitos funerarios.

De hecho, si existiera también en los contextos peninsulares una asociación mágica y simbólica entre el hilado y la manutención de la fertilidad y la fecundidad, hecho que como he podido comentar anteriormente parece muy plausible y que explicaría su concentración en espacios con funciones religiosas, la presencia de fusayolas y de otro instrumental textil en tumbas podría interpretarse en función de creencias relacionadas con el Más Allá y con el renacimiento de los difuntos.

Por otro lado, si a esa significación de base se hubiera sumado la metáfora de la vida como hilo anteriormente comentada y la consecuente relación mitológica entre el hilado y el destino, entonces esa presencia parecería todavía más justificada desde el punto de vista de la fenomenología religiosa, aunque se nos escape por completo la posible elaboración mitológica y escatológica subyacente al depósito de estos elementos en las tumbas.

Naturalmente, estas hipótesis de lectura deberán en el futuro ser analizadas en mayor profundidad, en función de tres líneas de investigación principales: por un lado, la recopilación de una base documental más amplia que sistematice los casos de piezas del tipo aquí estudiado depositadas en contextos sepulcrales; por otro lado, un estudio más exhaustivo de los patrones de distribución de esas piezas en función de factores demográficos, sociales y de género ( $c f$. Rafel 2007; Rísquez y García Luque 2012), que permita cotejar las explicaciones simbólicas aquí presentadas con las pautas específicas de incorporación del instrumental textil en los ajuares, ayudando a concretar la incidencia y vigencia social de las posibles creencias antes comentadas, así como evidenciar posibles matices locales/regionales que seguramente habrán existido (Rísquez y García Luque 2012); y, por fin, un análisis sistemático de las evidencias literarias e iconográficas sobre los posibles nexos entre la simbología del huso y del hilado con la esfera de la muerte que permita validar o negar algunas de las conjeturas avanzadas en este estudio.

Sin embargo, estas líneas de trabajo exceden los límites de esta contribución, por lo que quedaría solamente señalar que los materiales de la necrópolis de Alcácer do Sal aquí presentados vienen a ampliar la muestra de instrumental textil presente en ámbitos funerarios y expandir el área de difusión de este particular fenómeno, que debe así leerse en el marco de afinidades y convergencias a nivel del ritual funerario que merecen estudio más detallado en un futuro que se desea próximo.

\section{NOTAS}

1. La cuantificación de las piezas se ha realizado según el método del número mínimo de individuos (NMI), tal y como establecido en el protocolo de Mont Beauvray (Protocole Beauvray 1998).

2. Pagana lege in plerisque italiae praedis cavetur, ne mulieres per itinera ambulantes torqueant fusos aut omnino detectos ferant, quoniam adversetur id omnium spei, praecipue frugum (Nat. Hist. 28.5).

\section{AGRADECIMIENTOS}

Me gustaría expresar mi gratitud a Teresa Rita Pereira por todo su apoyo durante la elaboración del presente estudio y por haberme cedido el modelo para la tabla tipológica de la figura 6.

\section{BIBLIOGRAFÍA}

ALCALÁ-ZAMORA, L. (2003): La necrópolis Ibérica de Pozo Moro, Madrid.

ALFARO, C. (1986): El hilado y el tejido antiguo en el simbolismo del puteal, Coloquio sobre el Puteal de la Moncloa, Madrid, 171-180.

ANGELIS, S. de (1992): Moirai, Lexicon Iconographicum Mythologiae Classicae Vol. VI.1, Zurich/ München/ Düsseldorf, 636-648. 
ARANEGUI, C.; JODIN, A.; LLOBREGAT, E.; ROUILLARD, P.; UROZ, J. (1993): La nécropole ibérique de Cabezo Lucero (Guardamar del Segura, Alicante), Madrid.

ARRUDA, A. M. (1999-2000): Los Fenicios en Portugal. Fenicios y mundo indígena en el centro y sur de Portugal (siglos VIII-VI a.C.), Barcelona.

ARTHUR, Ma de L. C. (1952): Necrópolis de Alcácer-do-Sal (Colección del Prof. Dr. Francisco Gentil), II CNA, Zaragoza, 369-380.

BALLESTRA PUECH, S. (1999): Les Parques. Essai sur les figures du destin dans la littérature occidentale, Toulouse.

BARBER, E. J. W. (1991): Prehistoric Textiles, Princeton.

BEIRÃO, C. de M. (1990): Epigrafia da Idade do Ferro do Sudoeste da Península Ibérica. Novos dados arqueológicos, Estudos Orientais I, 107-118.

BEK-PEDERSEN, R. (2011): The Norns in Old Norse Mythology, Edimburgo.

BERROCAL-RANGEL, L. (2003): El instrumental textil en Cancho Roano: consideraciones sobre sus fusayolas, pesas y telares, Cancho Roano VIII. Los Materiales Arqueológicos I (S. Celestino, ed.), Badajoz, 213-297.

BERROCAL-RANGEL, L.; MAFFIOTTE, I. B.; RUIZ TRIVIÑO, C. (1994): Las fusayolas, El altar prerromano de Castrejón de Capote. Ensayo etnoarqueológico de un ritual céltico en el suroeste peninsular (L. Berrocal-Rangel, dir.), Madrid, 201-230.

BLÁNQUEZ, J. J. (1990): La formación del mundo ibérico en el Sureste de la Meseta. Estudio arqueológico de las necrópolis ibéricas de la provincia de Albacete, Albacete.

BRITO, M. A. de A. e (1968): Contributo para a classificação de alguns achados de Alcácer do Sal (Época Pré-Romana), Tesis de Licenciatura inédita, Facultad de Letras de la Universidad de Coimbra.

CABRERA, P.; GRIÑÓ, B. (1986): La Dama de Baza: ¿una diosa tejedora en el allende?, Coloquio sobre el Puteal de la Moncloa, Madrid, 193-203.

CALADO, D.; GOMES, M. V. (2006): Quinta da Queimada (Lagos): a necrópole da II Idade do Ferro, Revista Portuguesa de Arqueologia 9 (2), 171-185.

CARDITO, L. M. (1996): Las manufacturas textiles en la Prehistoria: las placas de telar en el Calcolítico peninsular, $Z e$ phyrus 49, 125-145.

CASTRO, Z. (1980): Fusayolas ibéricas: antecedentes y empleo, Cypsela III, 127-146.

CORREIA, V. (1925a [1971]): Uma conferência sobre a Necrópole de Alcácer do Sal, Obras, Vol. IV: Estudos Arqueológicos, Coimbra, 151-168.

CORREIA, V. (1925b [1971]): Fechos de cinturão da Necrópole de Alcácer do Sal, Obras, Vol. IV: Estudos Arqueológicos, Coimbra, 187-195.

CORREIA, V. (1925c [1971]): Um amuleto egípcio da Necrópole de Alcácer do Sal, Obras, Vol. IV: Estudos Arqueológicos, Coimbra, 195-201.
CORREIA, V. (1928 [1971]): Escavações realizadas na Necrópole Pré-Romana de Alcácer do Sal em 1926 e 1927, Obras, Vol. IV: Estudos Arqueológicos, Coimbra, 169-179.

CORREIA, V. (1930 [1971]): As fíbulas da Necrópole de Alcácer do Sal, Obras, Vol. IV: Estudos Arqueológicos, Coimbra, 181-186.

CUADRADO, E. (1987): La necrópolis ibérica de El Cigarralejo (Mula, Murcia), Madrid.

DASEN, V. (2011): Le pouvoir des femmes: des Parques aux Matres, Des Fata aux Fées. Régards croisées, de l'Antiquité à nos jours (M. H. D. de la Rochère, V. Dasen, dirs.), Lausanne, 115-146.

DIETRICH, B. C. (1962): The Spinning of Fate in Homer, Phoenix 16 (2), 86-101. DOI: https://doi.org/10.2307/1086943

FABIÃO, C. (1998): O Mundo Indígena e a sua Romanização na Área Céltica do actual território português, Tesis Doctoral inédita, Facultad de Letras de la Universidad de Lisboa.

FRAZER, J. (1935): The Golden Bough. A Study in Magic and Religion, New York.

GIANNOULIS, M. (2010): Die Moiren. Tradition und Wandel des Motivs der Schicksalsgöttinen in der antiken und byzantinischen Kunst, Münster.

GOMES, F. B. (2015): The Olival do Senhor dos Mártires necropolis (Alcácer do Sal, Portugal) in the context of the Iron Age funerary practices of the Southwestern Iberian Peninsula, Death as Archaeology of Transition: Thoughts and Materials (L. Rocha, P. Bueno, G. Branco, G.), Oxford, 327341.

GOMES, F. B. (2016): Contactos culturais e discursos identitários na I Idade do Ferro do Sul de Portugal (sécs. VIII - V a.n.e.): leituras a partir do registo funerário, Tesis Doctoral inédita, Universidad de Lisboa.

GREENE, W. C. (1944): Moira: Fate, Good and Evil in Greek Thought, Cambridge. DOI: https://doi.org/10.4159/harvard.9780674282421

GUÉRIN, P. (2003): El Castellet de Bernabé y el horizonte ibérico pleno edetano, Valencia.

HELENO, M. (1951): Arqueologia de Elvas. Notícia preliminar, O Arqueólogo Português S.2:I, 83-94.

HORN, F. (2011): Ibères, Grecs et Puniques en Extrême Occident. Les terres cuites de l'espace Ibérique du VIIIe au II siècle av. J.-C., Madrid.

IZQUIERDO, I. (2001): La trama del tejido y del vestido femenino en la cultura ibérica, Tejer y vestir. De la Antigüedad al Islam (M. Marín, ed.), Madrid, 287-312.

KRAUSE, W. (1936): Die Ausdrücke für das Shicksal bei Homer, Glotta 25:1/2, 143-152.

LINDOW, J. (2001): Norse Mythology. A Guide to the Gods, Heroes, Rituals and Beliefs, Oxford.

LÓPEZ MIRA, J. A. (1995): La actividad textil durante la Edad del Bronce en la Provincia de Alicante: las fusayolas, XXI CNA, Zaragoza, 785-797. 
LUCAS, M. R. (1992): Sociedad y religión a través de las necrópolis ibéricas, Congreso de Arqueología Ibérica: las necrópolis (J. Blánquez, V. Antona del Val, eds.), Madrid, 189-205.

LUÍS, E. (2014): "Nunca a boa fiandeira ficou sem camisa". Os cossoiros da Fraga dos Corvos (Macedo de Cavaleiros), Almadan II:19, 105-112.

MARTÍNEZ VALLE, A.; CASTELLANO, J. J. (1997): Conjunto de fusayolas ibéricas de dos cuevas santuario de la comarca de Requena-Utiel, XXIII CNA, Vol. 1, Elche, 525-536.

MOLINA, M. (1986): Iconografía de las Moirai en el Mundo Antiguo, Coloquio sobre el Puteal de la Moncloa, Madrid, 119-124.

NOSCH, M. L. B.; HARLOW. M.; FANFANI, G. (eds.) (2016): Spinning Fates and the Song of the Loom: the use of textiles, clothing and cloth production as metaphor, symbol and narrative device in Greek and Latin literature, Londres.

OLMOS, R. (2001): El simbolismo del tejer y del vestido en la Odisea, Tejer y vestir. De la Antigüedad al Islam (M. Marín, ed.), Madrid, 287-312.

PAIXÃO, A. C. (1970): A necrópole do Senhor dos Mártires, Alcácer do Sal. Novos elementos para o seu estudo, Tesis de Licenciatura inédita, Facultad de Letras de la Universidad de Lisboa.

PAIXÃO, A. C. (1983): Uma nova sepultura com escaravelho da necrópole proto-histórica do Senhor dos Mártires, Alcácer do Sal, O Arqueólogo Português S.4:1, 273-286.

PAIXÃO, A. C. (2001): Alcácer do Sal proto-histórica no contexto mediterrânico, Os Púnicos no Extremo Ocidente, Lisboa, 149-172.

PAIXÃO, A. C. (2014): A necrópole do Olival do Senhor dos Mártires (Alcácer do Sal). Novos elementos para o seu estudo, Estudos Arqueológicos de Oeiras 21, 429-460.

PEREIRA, M. H. da R. (1962): Greek Vases in Portugal, Coimbra.

PEREIRA, T. R. (2013): Por um fio: tipologia e função do conjunto de cossoiros de Cabeça de Vaiamonte (Monforte/ Portugal), Arqueologia em Portugal: 150 anos (J. M. Arnaud, A. Martins, C. Neves, eds.), Lisboa, 681-691.

PIRENNE-DELFORGE, V.; PIRONTI, G. (2011): Les Moires entre la naissance et la mort: de la représentation au culte, Des Fata aux Fées. Régards croisées, de l'Antiquité à nos jours (M. H. D. de la Rochère, V. Dasen, dirs.), Lausanne, 93-113.

PONTE, S. da (1985): Algumas fíbulas de Alcácer do Sal, $O$ Arqueólogo Português S.IV:3, 137-154.

PRESEDO, F. J. (1982): La necropolis de Baza, Madrid.

RAFEL, N. (2007): El textil como indicador de género en el registro funerario ibérico, Interpreting Household Practices: reflections on the social and cultural roles of maintenance activities (P. González Marcén, C. Masvidal, S. Montón, M. Picazo, eds.), Barcelona, 115-246.
RAHMSTORF, L. (2015): An introduction to the investigation of archaeological textile tools, Tools, Textiles and Contexts. Investigating textile production in the Aegean and Eastern Mediterranean Bronze Age (E. A. Strand, M.-L. Nosch, eds.), Oxford, 1-23.

RÍSQUEZ, C.; GARCÍA LUQUE, A. (2012): Identidades de género y prácticas sociales en el registro funerario Ibérico. La necrópolis de El Cigarralejo, La Arqueología funeraria desde una perspectiva de género (L. Prados, C. López Ruiz, J. Parra, coords.), Madrid, 257-276.

ROUILLARD, P.; PAIXÃO, A. C.; VILLANUEVA-PUIG, M.-C.; DURAND, J.-L. (1988-1989): Les vases grecques d'Alcácer do Sal, O Arqueólogo Português 6-7, 43-108.

RUIZ DE HARO, M. I. (2012): Orígenes, evolución y contextos de la tecnología textil: la producción del tejido en la Prehistoria y Protohistoria, Arqueología y Territorio 9, 133-145.

SÁNCHEZ GÓMEZ, M. L. (2002): El santuario de El Cerro de los Santos (Montealegre del Castillo, Albacete). Nuevas aportaciones arqueológicas, Albacete.

SÁNCHEZ, J. L.; QUESADA, F. (1992): La necrópolis ibérica del Cabecico del Tesoro (Verdolay, Murcia), Congreso de Arqueología Ibérica: las necrópolis (J. Blánquez, V. Antona del Val, eds.), Madrid, 349-396.

SCHEID, J.; SVENBRO, J. (1996): The Craft of Zeus. Myths of Weaving and Fabric, Cambridge.

SCHÜLE, W. (1969): Die Meseta-kulturen der Iberischen Halbinsel: Mediterrane und Eurasische elemente in früheisenzeitlichen kulturen südwesteuropas, Berlin.

SILVA, J. P. N. da (1875): Uma necrópolis romana em Portugal, Boletim da Real Associação dos Architectos Civis e Archeologos Portugueses, S.I:6, 91.

SIMEK, R. (2007): Dictionary of Northern Mythology, Woodbridge.

SUS, M. L. de (1986): Fusayolas del poblado celtibérico de Los Castellares (Herrera de los Navarros, Zaragoza. I. Tipología y función, Boletín del Museo de Zaragoza 5, 183-208.

TORRES, M. (1999): Sociedad y Mundo Funerario en Tartessos, Madrid.

VEIGA, S. P. M. E. (2005 [1891]): Antiguidades Monumentaes do Algarve, Vol. 4, Faro.

VÍLCHEZ, M. (2015): Tejido y rito en espacios de culto Iberos: las fusayolas como objeto de estudio, Revista Atlántica-Mediterránea, 17, 281-288. 